DR. LOUISA G GORDON (Orcid ID : 0000-0002-3159-4249)

Article type : Original Article

\title{
The effects of a multidisciplinary high-throughput skin clinic on healthcare costs of organ transplant recipients
}

Running head: Effects of a skin clinic on healthcare costs

L. G. Gordon ${ }^{1,2,3^{*}}$, A. J. Rodriguez-Acevedo ${ }^{1}$, K. Papier ${ }^{1}$, K.Khosrotehrani ${ }^{4,5}$, N.

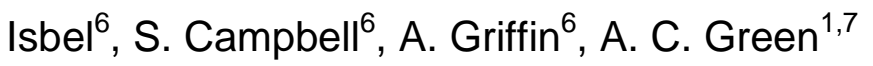

1. QIMR Berghofer Medical Research Institute, Population Health Department, Brisbane, Queensland, Australia

2. Queensland University of Technology, School of Nursing, Institute of Health and Biomedical Innovation, Brisbane, Queensland, Australia

3. The University of Queensland, School of Medicine, Brisbane, Queensland, Australia

4. Department of Dermatology, Princess Alexandra Hospital, Brisbane, Queensland, Australia

5. The University of Queensland, UQ Diamantina Institute, Translational Research Institute, Woolloongabba, Queensland, Australia

6. Department of Nephrology, Princess Alexandra Hospital, Brisbane, Queensland, Australia

This article has been accepted for publication and undergone full peer review but has not been through the copyediting, typesetting, pagination and proofreading process, which may lead to differences between this version and the Version of Record. Please cite this article as doi: $10.1111 /$ jdv. 15458

This article is protected by copyright. All rights reserved. 
7. CRUK Manchester Institute and Faculty of Biology Medicine and Health, University of Manchester, Manchester Academic Health Science Centre, Manchester, UK

${ }^{*}$ Corresponding author: Louisa Gordon

QIMR Berghofer Medical Research Institute 300 Herston Rd, Brisbane, QLD 4006, Australia

Tel: +61 738453502

Email: louisa.gordon@qimrberghofer.edu.au

Funding The work was funded by an Enabling Grant from the Australian Skin and Skin Cancer Research Centre.

Conflict of Interest The authors state no conflicts of interest.

\section{Abstract}

Background: A long-term complication among organ transplant recipients (OTRs) is skin malignancies which are associated with level and duration of immunosuppressive treatment, sun exposure and age. Dermatological surveillance is recommended for OTRs at high risk of skin malignancies, but evidence is lacking on the benefits of such services.

Objective: To examine the economic impact on patients and on the hospital service of a multidisciplinary high-throughput skin cancer Clinic in Brisbane, Australia, dedicated to dermatological and surgical care of high-risk OTRs. 
Methods: In a pre-post design, hospital admission and cost data were obtained for 101 consecutively-enrolled study participants from 12 months prior to the introduction of the Clinic (to February 2016), the 3-month 'run-in' period (March to May 2016), and 12 months subsequent (to June 2017). Differences between preand post-Clinic hospital costs were tested using non-parametric bootstrapping and interrupted time series analysis. A survey of patient out-of-pocket costs and perceived financial burden was also undertaken during the Clinic.

Results: Overall hospital costs were higher after the Clinic but 3-monthly hospital costs for skin procedures trended downwards. Despite 3-monthly mean hospital visits increasing from 85 to 314 , mean 3-monthly costs reduced by AU $\$ 1,491$ $(p<0.001)$ indicating greater cost-efficiency. Total patient out-of-pocket costs were AU $\$ 18,377$ over 3 months.

Conclusion: Clinical costing data revealed higher, more rapid throughput, and significantly lower per patient costs pre- and post- establishment of a multidisciplinary skin cancer Clinic for OTRs.

Key words: organ transplant, hospital costs, out-of-pocket expenses, financial wellbeing, cost-analysis 


\section{Introduction}

Major advances in organ transplantation have seen growing numbers of organ recipients worldwide (1). In the US, there were 34,771 solid organ transplantations performed in 2017 an increase of $23 \%$ over the previous decade (2). In Australia, over 10,000 individuals have received organ transplants since 2009 , with increasing rates of transplantation due to Australia's program to encourage organ and tissue donations (3). However after transplantation patients require regular, life-long followup with extensive use of medical services and resources to address ongoing health needs and maintain improved quality of life (4).

Management of OTRs after the early post-transplant period varies among countries and institutions with aftercare performed by physicians, surgeons and/or general practitioners (4). Clinical practice guidelines recommend outpatient surveillance of OTRs should occur at least every 3-4 months (4). Since the after-effects of transplantation span many health aspects from metabolic disturbances, skin conditions, to cardiovascular conditions, care is ideally multi-disciplinary.

A key long-term complication among OTRs is skin malignancy whose incidence is an order of magnitude higher than in the general population (5). Skin cancers are associated with level and duration of immunosuppressive treatment, sun exposure and age. In Australia, with its high ambient ultraviolet (UV) environment and its population of largely European ancestry, high lifetime UV exposure results in very high keratinocyte cancer risk such that dermatological surveillance and sun protection advice are essential (5) (6). However dermatological care is not integrated into routine follow-up care of OTRs in Australia as it is in other countries $(6,7)$. This This article is protected by copyright. All rights reserved. 
means that OTRs must follow the usual referral pathways, appointment bookings and waiting times in order to access a hospital dermatologist. The OTR would typically face multiple visits, lengthy delays and inconvenience.

To address this lack, the Princess Alexandra Hospital Transplant Skin Clinic (hereafter 'the Clinic') was established in Queensland, Australia, in March 2016 to provide expert dermatology and surgical care and expedite skin cancer treatments for very high-risk OTRs in the state $(8,9)$. As part of a broader Clinic evaluation $(8$, 9), the purpose of this study was to quantify: 1) the financial burden incurred by OTRs for their ongoing related healthcare, and 2) hospital costs related to skin cancer management before and after establishment of the Clinic.

\section{Methods}

\section{Study population}

All adult OTRs, or those with organ failure, lymphoproliferative diseases and/ or under immunosuppressive treatment who were referred to the Clinic by a specialist (nephrologist, transplant physician and/or dermatologist from the Princess Alexandra Hospital) during the enrolment period December 2016 to May 2017 (Figure1) were eligible to take part $(8,9)$. Patients were required to comprehend the study requirements and give informed consent. The study was approved by the QIMR Berghofer Human Research Ethics Committee (P2257) and the Metro South Human Research Ethics Committee (HREC/16/QPAH/703). 


\section{Transplant skin clinic}

The weekly Clinic provides "on the spot" high-throughput treatment of skin cancers for referred patients (9). It is staffed by: 1) a dermatology team (one consultant, multiple specialist trainees); 2) a surgical team (senior surgeon who determines optimal excision procedure, several surgical trainees, and junior doctors assisting); and 3) a transplant team, many of whom cross-participate in the surgical team (10). Plastic surgeons, radiation oncologists, kidney and liver physicians are on call. An average of eight patients are treated per Clinic (10), with any additional complex surgeries booked elsewhere in the hospital .

\section{Study Design}

The study used a single group, pre- and post-intervention design for analysis of the administrative hospital admissions and costing data. Hospital data were obtained for all study participants from 12 months prior to the introduction of the Clinic (March 2015 to March 2016), the 3-month 'run-in' period when the clinic started (March 2016 to May 2016) and 12 months afterward (June 2016 to June 2017) (Table 1). The study also included a self-administered survey about patients' personal details, quality of life and out-of-pocket expenses over the previous 3 months (from study enrolment). The personal burden of managing skin cancer was intended to be a snapshot and not a comparative analysis of pre- and post-Clinic time points.

This article is protected by copyright. All rights reserved. 


\section{Data Collection}

Administrative hospital admission, procedures, and costs: Hospital data were available only from the Princess Alexandra Hospital and no other hospitals patients may have attended. Nor did we collect data on health system costs in private settings. Data were extracted from routine administrative clinical costing datasets and included: hospital admission start and end dates, type of attendance (outpatient, inpatient, emergency), same day admission flag, major diagnostic category, admission ward, principal diagnosis (International Classification of Diseases (ICD)10 code type and code), morphology (ICD-code), procedures, procedure dates, Australian-Refined Diagnosis Related Groups (AR-DRG) code, actual cost, direct cost, overhead cost, cost centre. The AR-DRG cost 'buckets' for inpatient episodes of care account for doctors' and nurses' time, other health professionals' time, all consumables used in procedures and hospital overheads (See relevant codes, Appendix 1). Specialist consultations in the Clinic were initially voluntary but the dermatologists are now remunerated for their clinic time in the outpatient setting. These costs were not part of this analysis.

Patient self-report: At enrolment, participants completed a self-administered questionnaire covering personal details (age, sex, marital status, occupation, education level, country of birth, ancestry, and general health rating) and medical history, skin type and sun exposure/ protection habits, out-of-pocket costs for skin care (travel, accommodation, treatment costs for skin cancer, sun protection items). Financial well-being was measured using the 11 -item validated COmprehensive Score for financial Toxicity (COST)-Functional Assessment of Chronic Illness Therapy (FACIT) or COST-FACIT questionnaire that includes items on financial concerns (eg worry about financial problems, being able to meet monthly expenses, This article is protected by copyright. All rights reserved. 
feeling financially stressed), with Likert responses ranging from 'not at all' to 'very much'.

\section{Analyses}

Frequencies and percentages were used to describe categorical variables, and means and standard deviation, for continuous variables. Hospital costs were aggregated and presented by mean per person and mean per admission. As healthcare costs are typically right-skewed, with a few patients having extreme costs, we presented median, minimum and maximum values. Costs were presented in 2016/2017 Australian dollars for inpatient (or admitted patient), outpatient (or nonadmitted patient) and total costs. Patients categorised as 'inpatients' undergo formal admission procedures by the hospital, but this is unrelated to the time spent in hospital, hence patients can be admitted and discharged on the same day.

Individual-level pre- and post-Clinic hospital admission and cost data were aggregated into 3-monthly blocks to align with the expected frequency of post-Clinic visits. The resources used for the cost analysis were those for skin lesion/cancerrelated services only (Appendix 1). To test the differences between pre- and postClinic mean costs and account for skewness $(=5.07), 95 \%$ confidence intervals (bootstrap percentile interval) were computed using non-parametric bootstrapping analyses with 10,000 replacements (11). Bootstrap analysis was also used to estimate the probability that total post-Clinic costs were lower than pre-Clinic costs. To further assess the effect of Clinic establishment on total costs we performed a gamma segmented regression analysis using a step and slope change model (12) to account for interaction between time and total post-clinic monthly cost. Personal expenses were aggregated for the total sample and covered the previous 3-month 
period from the survey. COST-FACIT scores were calculated according to the scoring algorithm ranging from 0 to 44 with higher scores representing more favorable financial well-being. Analyses were performed using $R$ (13).

\section{Results}

Participation rate and description of participants

Of 111 Clinic attendees invited to participate, 101 agreed (91\% participation). Most participants were men $(78,77 \%)$ with a mean age of 63 years (sd 10), $77(76 \%)$ had British or Irish heritage, 89 were OTRs (79 kidney, 8 liver, 1 lung and 1 heart) and the remaining 12 were awaiting transplantation or had a history of many skin cancers. $(14,15)$ On average, OTRs were 14 years from their initial transplant and 49 (49\%) were on triple immunosuppressive therapy. Non-participants tended to be male $(9,91 \%)$ and younger (mean age 55 ) than participants (Table 2). A large proportion (41\%) of OTR participants were considered low income (defined as $<A \cup \$ 30,000$ annual household income), 34 (34\%) were in paid work and $56(56 \%)$ had not completed high school. Around half had skin with a tendency to burn on acute sun exposure, nearly one-third had outdoor occupations during their lives and $42(42 \%)$ had outdoor leisure activities.

\section{Personal costs and financial strain}

During a 3-month follow-up period, the participants visited the Clinic a median of 2 times (interquartile range 1-3) per person and 224 times in total. The median traveling distance was $40 \mathrm{~km}$ (range 5 - 1200). Most traveled by car to the Clinic and This article is protected by copyright. All rights reserved. 
$67 \%$ incurring parking fees (total for group AU\$1189). Twelve OTRs incurred accommodation fees. Some $28 \%$ of employed participants required time off work to attend the Clinic (251 total hours) and $8 \%$ of carers required time off work. In total, the out-of-pocket costs for 101 OTRs were $\$ 18,377$ for 3 months. These included: a) skin cancer-related services; general practitioner and specialist visits outside the Clinic, excisions, creams, tests, radiation, and medications (AU\$7,074); and b) purchasing sun protection items: sunscreen, broad-brimmed hats, clothing like arm protectors, and sunglasses (AU $\$ 11,303)$. The mean psychological burden of financial costs measured on the COST-FACIT was 29.6 (SD 9.3). Low-scoring items on the COST-FACIT indicated that patients were most concerned about the future, being unable to contribute at work and concerns about keeping their job and income.

\section{Hospital costs}

Both total inpatient and outpatient visits increased in the post-Clinic compared with pre-Clinic period (Table 3). Total costs for skin-related hospital visits showed AU $\$ 220,419$ pre-Clinic for 85 visits, $A \cup \$ 113,083$ immediately after the Clinic was established for 54 visits and, AU\$346,196 post-Clinic for 314 visits (Table 3, Fig. 1).

Overall cost increases were driven by extreme high-costs of a few plastic surgeries and skin debridement (Table 3, Fig. 2). However, 3-monthly mean and median costs for inpatient visits per patient decreased from mean AU\$2,523; median AU\$1,920 before the Clinic to mean $\mathrm{AU} \$ 1,654$ and median $\mathrm{AU} \$ 223$ post-Clinic. Similarly, mean and median costs for outpatient visits per patient decreased from mean $A \cup \$ 3,696$; median AU $\$ 3,696$ before the Clinic to mean AU\$325 and median AU\$286 post-

Clinic, despite there being only two pre-Clinic outpatient visits on average (Table 2) 
(the Clinic was not then operating formally on an outpatient basis and so patients were admitted for all procedures). Mean 3-monthly costs after the Clinic was established, reduced significantly by $A \cup \$ 1,491$ (95\%Cl: AU\$1,024, AU\$1,966), $p<0.001$. Correlation between hospital cost over time (pre- and post-Clinic) was not statistically significant $(p=0.48)$ but post-Clinic cost tended to decrease (Fig. 3$)$.

\section{Discussion}

Our study shows economic savings accruing from a dedicated multidisciplinary transplant skin Clinic at a large metropolitan hospital in Australia. Before the Clinic, the estimated annual hospital cost burden for treating skin cancers in OTRs was AU $\$ 220,419$. As expected, immediately on inception the Clinic experienced high volumes of all skin-related attendances that then settled to reduced 3-monthly costs consistent with the more rapid throughput, as well as significantly lower per patient costs in the 12 months after the Clinic was established. Total hospital costs for skin procedures were higher overall in the 12 months after the Clinic was established but were trending downwards (June 2016-May 2017) and showed greater cost efficiency than the 12 months before the Clinic started. Higher overall costs were attributed to the additional capacity of Clinic staff to manage many more patients than managing these same patients within usual routine dermatology care. Cost efficiencies were likely driven by the high-throughput nature of the Clinic and the switch to low-cost outpatient care, avoiding the time and resources needed for processing inpatient admissions. We believe the high costs in the or establishment period occurred because patients had not yet attended the transplant skin clinic and were still undergoing slower and more expensive inpatient appointments, given that the new 
clinic was at capacity with the influx of first-time patients. With a longer follow-up period, it is possible the costs would continue to decline with less inpatient care. With collaborative care, frequent follow-up will potentially prevent advanced skin cancer disease as it will potentially be caught earlier, further lowering costs.

The clinical benefits of the Clinic have been previously reported $(8,10)$. Establishment of the Clinic led directly to more skin cancers being detected and treated consistent with the principle that a dermatology and surgery clinic for OTRs facilitates prompt treatment of skin malignancies and ultimately, should lower skin cancer metastases and fatalities. For the large investment in transplantation to be realised in OTRs' longevity and to minimize patient burden, it is important that they be managed promptly and that their care incorporates sun protection advice (8), early detection and intervention of skin cancers (16).

Our findings indicate that the out-of-pocket costs incurred by patients were substantial in the short-term. This is important since many Clinic patients were on low incomes or not in paid employment. The Clinic offers a 'one-stop shop' for patients that significantly eased the financial burden and delay in skin cancer treatment including when patients previously received this care by their primary care physician or in a private dermatology clinic. During patient interactions with the researchers in the Clinic, patients were very satisfied with the performance of the Clinic and liked attending because they received all their skin cancer treatment at a single visit and could avoid worry while they waited for surgery.(9) One-third of OTRs had their skin cancers surgically treated on the same day and the remaining patients were treated promptly: $50 \%$ of patients treated within seven days(9). Some patients 
returned for skin treatment in separate visits due to, for example, being unwell, having numerous cancers or because they required more complicated plastic surgery.(9)

Out-of-pocket medical costs are a serious burden for many patients $(17,18)$, in particular for cancer populations $(19,20)$ and among those with chronic diseases (14, 15). Similar to our findings, costs for medications and medical services constitute a significant proportion of these personal costs (20) and financial strain has adverse impacts on quality of life (21). Inability to pay for medicines can lead to nonadherence (22) and disengagement with healthy behaviours (23), both of which are essential for optimal self-management in OTRs. While the Clinic offered some relief to patient medical costs via fewer hospital visits, these could be further reduced by providing free sunscreen to patients at the Clinic to encourage and sustain good sun protective practice. An important new insight arising from this study was the concern reported by OTRs for their employment or ability to continue working. This is consistent with other studies of OTRs where the circumstances and clinical demands of living with a graft hinder ability to work and maintain an income, creating a high degree of distress and financial hardship in some cases (24).

Our study is limited by the single-group pre-post design with relatively small numbers of participants. The lack of a control group and a non-randomised approach means confounding cannot be ruled out. However, in our study we enrolled a routine group of OTRs who were very similar to those from a large study of nearly 500 high-risk OTRs attending the Princess Alexandra Hospital.(5) We therefore propose that the findings are reasonably representative of OTRs attending a large metropolitan This article is protected by copyright. All rights reserved. 
specialist centre. There were also no changes to the way administrative data were collected or measured during our study, there were no other interventions that could affect our findings and regression to the mean was minimised with multiple counts of admissions over the period. Costs incurred by other private or public hospitals that patients were likely to use prior to the Clinic were outside the scope of this study and not collected. Therefore, our findings underestimate the full health system burden for managing skin conditions in participating OTRs and would likely exaggerate the cost reductions found post-Clinic. Strengths of this study were the use of administrative data to confirm hospital activities and billings over two years and the use of survey data that collectively provide a broad view of resource use by the hospital and patients respectively. A full economic evaluation would be beneficial to inform decision-makers on whether this service demonstrates cost-effective healthcare and is worthy of broader adoption. This would require comparison of a Clinic and nonClinic group, and a larger study with longer follow-up, and a sample powered to measure clinical benefits.

\section{Conclusion}

The establishment of a proactive multidisciplinary dermatology and surgery skin clinic for OTRs offered patient-centered care and appeared to alleviate the economic and health burden for patients while potentially improving cost-efficiencies in a large public hospital. Further evidence on cost-effectiveness is required to support these findings.

This article is protected by copyright. All rights reserved. 


\section{References}

1. Johnson RJ, Bradbury LL, Martin K, Neuberger J. Organ donation and transplantation in the UK-the last decade: a report from the UK national transplant registry. Transplantation. 2014;97(Suppl 1):S1-S27..

2. United Network for Organ Sharing. Transplant trends USA: UNOS; 2018 [Available from: https://unos.org/data/transplant-trends/\#transplants_by_organ_type+year+2017 (Access date 7 July 2018)

3. ANZ DATA Organ Donation Registry. Australian Donation and Transplantation Activity Report 2017. Canberra: Australian Government Organ and Tissue Authority; 2017.

4. Geusau A, Pohanka E. After care in OTRs. In: The SCOPE Collaborative Group, editor. Skin Cancer after Organ Transplantation 2009. p. 405-15.

5. Iannacone MR, Sinnya S, Pandeya N, Isbel N, Campbell S, Fawcett J, et al. Prevalence of Skin Cancer and Related Skin Tumors in High-Risk Kidney and Liver Transplant Recipients in Queensland, Australia. The Journal of investigative dermatology. 2016;136(7):1382-6.

6. Christenson LJ, Geusau A, Ferrandiz C, Brown CD, Ulrich C, Stockfleth E, et al. Specialty clinics for the dermatologic care of solid-organ transplant recipients. Dermatologic surgery : official publication for American Society for Dermatologic Surgery [et al]. 2004;30(4 Pt 2):598-603.

7. Maurice PD, Fenton T, Cross N, Thomson IA, Rennie SC, van Rij AM. A dedicated dermatology clinic for renal transplant recipients: first 5 years of a New Zealand experience. The New Zealand medical journal. 2013;126(1369):27-33.

8. Papier K, Gordon LG, Khosrotehrani K, Isbel N, Campbell S, Griffin A, et al. Increase in preventive behaviour by organ transplant recipients after sun protection information in a skin cancer surveillance clinic. The British journal of dermatology. 2018;8(10):16836.

9. Papier K, Gordon LG, Khosrotehrani K, Isbel N, Campbell S, Griffin A, et al. Management of organ transplant recipients attending a high-throughput skin cancer surgery and surveillance clinic in Queensland. The British journal of dermatology. 2018;(accepted 9/7/18) .

10. Papier K, Gordon LG, Khosrotehrani K, Isbel N, Campbell S, Griffin A, et al. Management of organ transplant recipients attending a high-throughput skin cancer surgery and surveillance clinic in Queensland. The British journal of dermatology. 2018;13(10):17001.

11. Efron B, Tibshirani RJ. An introduction to the bootstrap: Chapman \& Hall; 1993.

12. Bernal JL, Cummins S, Gasparrini A. Interrupted time series regression for the evaluation of public health interventions: a tutorial. Int J Epidemiol. 2017;46(1):348-55.

13. R Core Team. R: A language and environment for statistical computing. URL http://www.Rproject.org/. Vienna, Austria; 2013.

14. Essue B, Kelly P, Roberts M, Leeder S, Jan S. We can't afford my chronic illness! The out-ofpocket burden associated with managing chronic obstructive pulmonary disease in western Sydney, Australia. J Health Serv Res Policy. 2011;16(4):226-31.

15. Islam MM, Yen L, Valderas JM, McRae IS. Out-of-pocket expenditure by Australian seniors with chronic disease: the effect of specific diseases and morbidity clusters. BMC public health. 2014;14:1008.

16. Ruegg CP, Graf N, Muhleisen B, Szucs TD, French LE, Surber C, et al. Squamous cell carcinoma of the skin induces considerable sustained cost of care in organ transplant recipients. J Am Acad Dermatol. 2012;67(6):1242-9..

17. Doggett J. Out of pocket, Rethinking health copayments https://cpd.org.au/2009/07/out-ofpocket-rethinking-health-copayments/. Sydney: Centre for Policy Development; 2009.

18. Gordon LG, Merollini KMD, Lowe A, Chan RJ. A Systematic Review of Financial Toxicity Among Cancer Survivors: We Can't Pay the Co-Pay. Patient. 2017;10(3):295-309..

19. Deloitte Access Economics. The financial impact of breast cancer in Australia November 2016 https://www.bcna.org.au/about-us/advocacy/research-reports/the-financial-impact-of-breastcancer/. Melbourne: Deloitte Access Economics; 2016.

This article is protected by copyright. All rights reserved. 
20. Gordon LG, Walker SM, Mervin MC, Lowe A, Smith DP, Gardiner RA, et al. Financial toxicity: a potential side effect of prostate cancer treatment among Australian men. European journal of cancer care. 2015.

21. Fenn KM, Evans SB, McCorkle R, DiGiovanna MP, Pusztai L, Sanft T, et al. Impact of financial burden of cancer on survivors' quality of life. Journal of oncology practice / American Society of Clinical Oncology. 2014;10(5):332-8.

22. Nekhlyudov L, Madden J, Graves AJ, Zhang F, Soumerai SB, Ross-Degnan D. Cost-related medication nonadherence and cost-saving strategies used by elderly Medicare cancer survivors. J Cancer Surviv. 2011;5(4):395-404.

23. Rezayatmand R, Pavlova M, Groot W. The impact of out-of-pocket payments on prevention and health-related lifestyle: a systematic literature review. Eur J Public Health. 2012.

24. Nour N, Heck CS, Ross H. Factors related to participation in paid work after organ

transplantation: perceptions of kidney transplant recipients. J Occup Rehabil. 2015;25(1):38-51.

This article is protected by copyright. All rights reserved. 
Table 1: Time periods of data collections

\begin{tabular}{|c|c|c|}
\hline 3-month period & Hospital cost data & $\begin{array}{l}\text { Patient out-of- } \\
\text { pocket data }\end{array}$ \\
\hline Mar/May 2015 & \multirow{4}{*}{$\begin{array}{l}12 \text { months } \\
\text { Pre-Clinic }\end{array}$} & \\
\hline Jun/Aug 2015 & & \\
\hline Sept/Nov 2015 & & \\
\hline Dec/Feb 2016 & & \\
\hline Mar/May 2016 & Clinic established & \\
\hline Jun/Aug 2016 & \multirow{4}{*}{$\begin{array}{l}12 \text { months } \\
\text { Post-Clinic }\end{array}$} & \\
\hline Sept/Nov 2016 & & \\
\hline Dec/Feb 2017 & & Baseline survey ${ }^{1}$ \\
\hline Mar/May 2017 & & \\
\hline
\end{tabular}

This article is protected by copyright. All rights reserved. 
Table 2: Participant characteristics and out-of-pocket expenses and financial burden at baseline

\begin{tabular}{|c|c|}
\hline & $(n=101)$ \\
\hline \multicolumn{2}{|l|}{ Age (years) } \\
\hline Mean (sd) & $63(10)$ \\
\hline Gender (male) & $78(77 \%)$ \\
\hline \multicolumn{2}{|l|}{ Highest level of education } \\
\hline Did not complete high school & $56(56 \%)$ \\
\hline Completed high school & $15(15 \%)$ \\
\hline Completed trade/technical qualification & $20(20 \%)$ \\
\hline Completed university/college degree & $9(9 \%)$ \\
\hline \multicolumn{2}{|l|}{ Travelling distance (home to Hospital) kms } \\
\hline Mean (sd) & $133(256)$ \\
\hline Median (min, max) & $40(5-1200)$ \\
\hline \multicolumn{2}{|l|}{ Usual mode of transport (n, \%) } \\
\hline Car & $68(67.3 \%)$ \\
\hline Public transport & $21(20.8 \%)$ \\
\hline Both car/public transport or other & $12(11.8 \%)$ \\
\hline Total parking fees & $\$ 1,189$ \\
\hline Total public transport fares & $\$ 1,834$ \\
\hline \multicolumn{2}{|l|}{ Accommodation required $(n, \%)$} \\
\hline Yes & $12(11.9 \%)$ \\
\hline No & $89(88.1 \%)$ \\
\hline Total accommodation payments & $\$ 760$ \\
\hline \multicolumn{2}{|l|}{ Financial support $(\mathrm{n}, \%)^{1}$} \\
\hline No & $78(77.2 \%)$ \\
\hline Yes: travel subsidy/other & $23(22.8 \%)$ \\
\hline Total financial support & $\$ 1,372$ \\
\hline \multicolumn{2}{|l|}{ Time off work required? } \\
\hline No & $73(72.3 \%)$ \\
\hline Yes & $28(27.7 \%)$ \\
\hline Total time off work taken (hours) & 251 \\
\hline \multicolumn{2}{|l|}{ Partner/carer - Time off work required? } \\
\hline No & $93(92.1 \%)$ \\
\hline Yes & $8(7.9 \%)$ \\
\hline Partner/carer - Total time off work taken (hours) & 124 \\
\hline \multicolumn{2}{|l|}{ Costs for skin cancer treatments: } \\
\hline General practitioner / specialist visits & $\$ 2,495$ \\
\hline Removal of skin lesion & $\$ 2,110$ \\
\hline Creams & $\$ 1,024$ \\
\hline Medical tests or imaging & $\$ 389$ \\
\hline Medications & $\$ 856$ \\
\hline Radiation or laser & $\$ 0$ \\
\hline Other treatment & $\$ 200$ \\
\hline Total & $\$ 7,074$ \\
\hline \multicolumn{2}{|l|}{ Costs for sun protection items } \\
\hline Yes & $68(67.3 \%)$ \\
\hline Sunscreen & $\$ 1,643$ \\
\hline Broad-brimmed hat & $\$ 1,805$ \\
\hline Clothing (rashie, arm protector) & $\$ 1,915$ \\
\hline Sunglasses & $\$ 4,865$ \\
\hline Other & $\$ 1,075$ \\
\hline Total & $\$ 11,303$ \\
\hline \multicolumn{2}{|l|}{ Financial well-being mean score (see below) } \\
\hline Mean (sd) score & $29.64(9.25)$ \\
\hline
\end{tabular}

1. Excludes Government support pensions, aged pension etc.

This article is protected by copyright. All rights reserved. 
Table 3: Number and type of hospital visits and costs (\$AU) for skin lesions or cancers, pre-Clinic, Clinicestablishment and post-Clinic $\left(n=101^{1}\right)$

\begin{tabular}{lccc}
\hline & Inpatient $^{2}$ & Outpatient & Total \\
\hline Pre-Clinic & & & \\
3-monthly & & & \\
Mean costs (sd) & $\$ 2,523(\$ 1,777)$ & $\$ 3,696(\$ 4,871)$ & $\$ 2,549(\$ 1,797)$ \\
Median costs (min, max) & $\$ 1,920(\$ 941, \$ 8,760)$ & $\$ 3,696(\$ 252, \$ 7,141)$ & $\$ 1,952(\$ 252, \$ 8,760)$ \\
Total period (12 months) & & & \\
No. visits & 83 & 2 & 85 \\
Total costs & $\$ 213,026$ & $\$ 7,393$ & $\$ 220,419$
\end{tabular}

Clinic-establishment or 'run-in' period
$\begin{array}{lccc}\text { 3-monthly } \\ \text { Mean costs (sd) } & \$ 2,004(\$ 2,377) & \$ 2,291(\$ 7,686) & \$ 2,094(\$ 4,657) \\ \text { Median costs (min, max) } & \$ 1,672(\$ 21, \$ 9,823) & \$ 518(\$ 65, \$ 32,110) & \$ 532(\$ 21, \$ 32,110)\end{array}$

Total period (3 months)
No. visits
37
17
54

Total costs

$\$ 74,136$

$\$ 38,947$

$\$ 113,083$

\begin{tabular}{|c|c|c|c|}
\hline \multicolumn{4}{|l|}{ Post-Clinic } \\
\hline \multicolumn{4}{|l|}{ 3-monthly } \\
\hline Mean costs (sd) & $\$ 1,654(\$ 2,951)$ & $\$ 325(\$ 626)$ & $\$ 1,129(\$ 2,269)$ \\
\hline Median costs (min, max) & $\$ 223(\$ 37, \$ 24,959)$ & $\$ 286(\$ 25, \$ 7,154)$ & $\$ 278(\$ 36, \$ 13,921)$ \\
\hline \multicolumn{4}{|l|}{ Total period (12 months) } \\
\hline No. visits & 182 & 131 & 314 \\
\hline Total costs & $\$ 302,849$ & $\$ 42,701$ & $\$ 346,196$ \\
\hline $\begin{array}{rr}\text { 1. } & \text { The } \\
& \$ 35 \\
& \$ 50 \\
\text { 2. } & \text { Man }\end{array}$ & $\begin{array}{l}\text { the } 12 \text { non-OTRs were no d } \\
\text { AU } \$ 19 ; \text { max: AU\$14,284) vs } \\
\text { U\$6 max : AU } \$ 2,245) \text { vs OTF } \\
\text { me day admissions }\end{array}$ & $\begin{array}{l}\text { OTRs in the study with } r \\
2 \text { (min: AU\$:16; max: } \$ 28 \\
\text { : AU\$1 max : AU\$3,707). }\end{array}$ & $\begin{array}{l}\text { rect costs: non-OTRs- median } \\
\text { indirect costs: non-OTRs- median }\end{array}$ \\
\hline
\end{tabular}

This article is protected by copyright. All rights reserved. 
Figure 1: Skin lesion/cancer procedures and mean costs pre-Clinic, Clinic establishment and post-Clinic

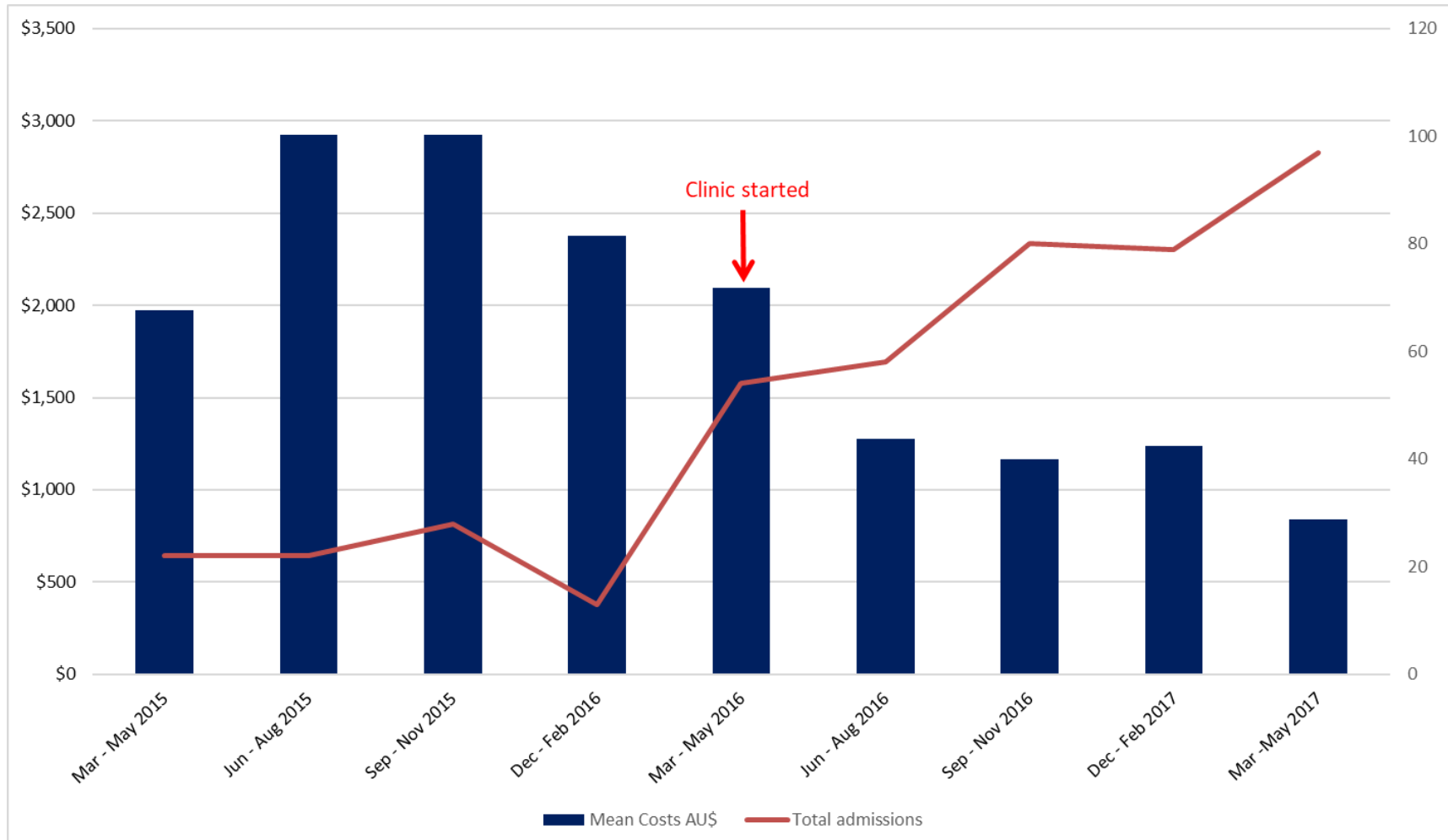

This article is protected by copyright. All rights reserved. 
Figure 2: Cost per patient admission for skin cancer procedures, pre-Clinic, Clinic establishment and post-Clinic $(n=101)$

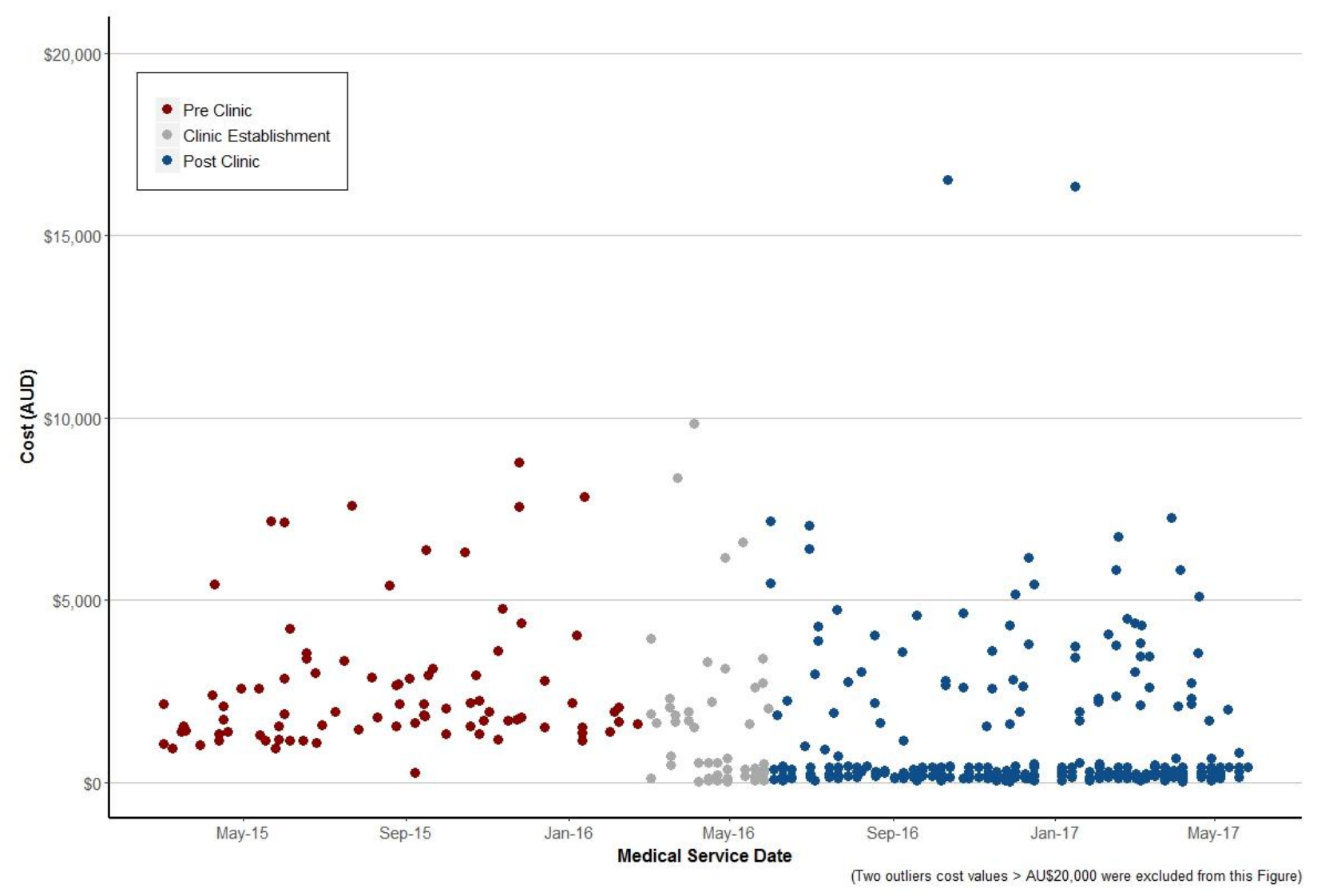

This article is protected by copyright. All rights reserved. 
Figure 3: Total hospital cost for skin cancer procedures, pre-Clinic and post-Clinic $(n=101)$

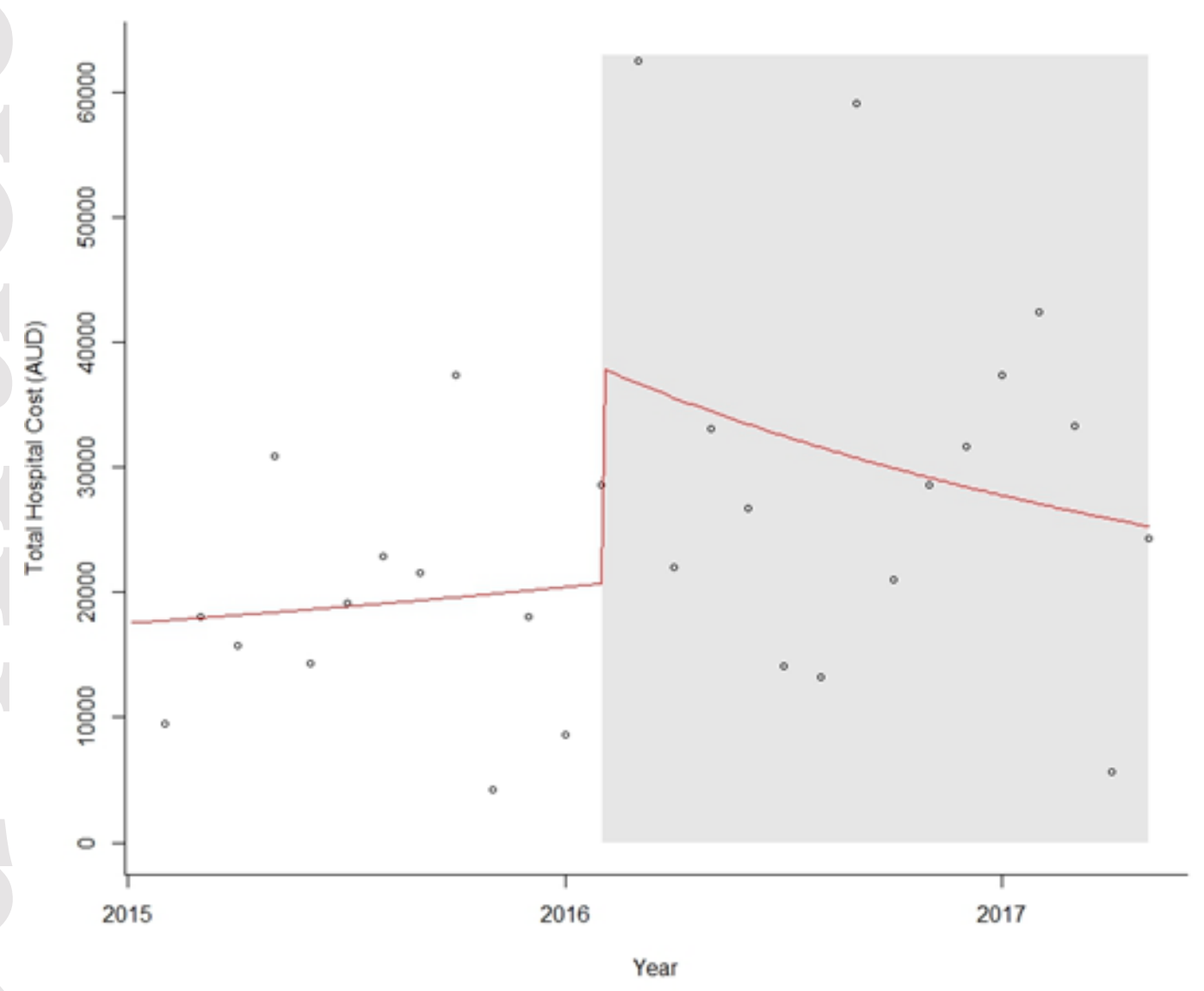

This article is protected by copyright. All rights reserved. 
Appendix 1: Skin cancer diagnosis and procedure codes included in the analysis

\begin{tabular}{|c|c|}
\hline \multicolumn{2}{|c|}{ Skin Cancer Diagnosis } \\
\hline ICD-10 Code & Description \\
\hline C44.0 & Malignant neoplasm of skin of lip \\
\hline C44.1 & Malignant neoplasm of skin of eyelid, including canthus \\
\hline C44.1 & Skin of eyelid, including canthus \\
\hline C44.2 & Malignant neoplasm of skin of ear and external auricular canal \\
\hline C44.3 & Malignant neoplasm of skin of other and unspecified parts of face \\
\hline C44.4 & Malignant neoplasm of skin of scalp and neck \\
\hline C44.5 & Malignant neoplasm of skin of trunk \\
\hline C44.6 & Malignant neoplasm of skin of upper limb, including shoulder \\
\hline C44.7 & Malignant neoplasm of skin of lower limb, including hip \\
\hline D03.6 & Melanoma in situ of upper limb, including shoulder \\
\hline D04.0 & Carcinoma in situ of skin of lip \\
\hline D04.1 & Carcinoma in situ of skin of eyelid, including canthus \\
\hline D04.2 & Carcinoma in situ of skin of ear and external auricular canal \\
\hline D04.3 & Carcinoma in situ of skin of other and unspecified parts of face \\
\hline D04.4 & Carcinoma in situ of skin of scalp and neck \\
\hline D04.5 & Carcinoma in situ of skin of trunk \\
\hline D04.6 & Carcinoma in situ of skin of upper limb, including shoulder \\
\hline D04.7 & Carcinoma in situ of skin of lower limb, including hip \\
\hline $\mathrm{D} 22.2$ & Melanocytic naevi of ear and external auricular canal \\
\hline D22.4 & Melanocytic naevi of scalp and neck \\
\hline $\mathrm{D} 22.5$ & Melanocytic naevi of trunk \\
\hline D22.5 & Melanocytic naevi of trunk \\
\hline D22.6 & Melanocytic naevi of upper limb, including shoulder \\
\hline D22.6 & Melanocytic naevi of upper limb, including shoulder \\
\hline D48.5 & Neoplasm of uncertain or unknown behaviour of skin \\
\hline \multicolumn{2}{|c|}{ Skin Cancer Procedures } \\
\hline MBS Code & Description \\
\hline $30023-00$ & Excisional debridement of soft tissue \\
\hline $30026-00$ & Repair of wound of skin and subcutaneous tissue of other site, superficial \\
\hline $30071-00$ & Biopsy of skin and subcutaneous tissue \\
\hline
\end{tabular}

This article is protected by copyright. All rights reserved. 


\begin{tabular}{|l|l|}
\hline $30189-01$ & Removal of other wart \\
\hline $30216-02$ & Other aspiration of skin and subcutaneous tissue \\
\hline $31205-00^{*}$ & Excision of lesion(s) of skin and subcutaneous tissue of other site \\
\hline $31230-01^{*}$ & Excision of lesion(s) of skin and subcutaneous tissue of nose \\
\hline $31230-02^{*}$ & Excision of lesion of skin and subcutaneous tissue of ear \\
\hline $31230-03^{*}$ & Excision of lesion of skin and subcutaneous tissue of lip \\
\hline $31230-04^{*}$ & Excision of lesion(s) of skin and subcutaneous tissue of finger \\
\hline $31235-00^{*}$ & Excision of lesion(s) of skin and subcutaneous tissue of other site of head \\
\hline $31235-01^{*}$ & Excision of lesion of skin and subcutaneous tissue of neck \\
\hline $31235-02^{*}$ & Excision of lesion(s) of skin and subcutaneous tissue of hand \\
\hline $31235-03^{*}$ & Excision of lesion(s) of skin and subcutaneous tissue of leg \\
\hline $31235-04^{*}$ & Excision of lesion(s) of skin and subcutaneous tissue of foot \\
\hline $45206-03$ & Local skin flap of ear \\
\hline $45439-00$ & Small split skin graft of other site \\
\hline $45451-24$ & Full thickness skin graft of other areas of face \\
\hline $45515-00$ & Revision of scar of other site < 7 cm in length \\
\hline $45665-00$ & Full thickness wedge excision of lip \\
\hline $45665-01$ & Full thickness wedge excision of eyelid \\
\hline $45665-02$ & Full thickness wedge excision of ear \\
\hline $46516-01$ & Eemoval of fingernail \\
\hline $90665-00$ & Nonexcisional debridement of skin and subcutaneous tissue \\
\hline $90686-01$ & \\
\hline
\end{tabular}

Items "*" marked are not listed in the current MBS database:

http://www.mbsonline.gov.au/internet/mbsonline/publishing.nsf/Content/news-2016-11-01-latest-news-Nov

This article is protected by copyright. All rights reserved. 